\title{
GLOBALISATION, LEXICAL BORROWING AND LANGUAGE CHANGE: A CASE STUDY OF MALAYALAM
}

\author{
Saratchandran Nair Velappan
}

\begin{abstract}
Malayalam is a language of the South Dravidian family of languages of India. Dravidian languages form one of the major groups of the Indian sub continent. Malayalam, is spoken in Kerala state, the southern most part of India, which is internationally recognized as a tourist destination and known as 'god's own country' for it's scenic and natural beauty. It has been reported that even in early part of the beginning of Christian era, there have been trade contacts with Greeks, Arabs and Chinese on the shores of Kerala. The present paper traces the historical development of lexical borrowing in Malayalam through various stages. When one talks of globalization, it is necessary to take in to account the phenomenon during the colonization stage also. It is also necessary to take into account the importancegiven by the father of the nation, Sri. Mahatma Gandhi, who emphasized the significance of the native and regional languages. Post independence India, saw an upsurge in the use of regional languages and an indigenization movement was/is seen. There have always been English vs. Regional language movements (even the latest press reports show) in Kerala and also in Karnataka, another state of India. After India embarked on a policy of liberalization and globalization, post 1991 saw an India as an emerging market, the growth of English have been phenomenal, coupled with the use of English
\end{abstract}


in Computer and transnational connectivity have marginalized the use of regional languages. Number of English medium schools have increased. It is in this context the study of lexical borrowings and adaptations are studied based on the news/TV media and also on Malayalam corpora of more than 10 lakh(1 million) words. Sample of English lexical items borrowed with frequency count is listed. In conclusion, we could say the impact of English is phenomenal and it is suggested, that steps have to be taken to protect and preserve a vernacular/regional language like Malayalam and culture in a multilingual, multiethnic set up of India in consonance with English. Though there have been efforts for localization, it is marginal. Otherwise in the rat race for globalization and liberalization, among the 1652 mother tongue speakers (as per the census of India,1971, many languages and cultures would be endangered. For many major languages it may be happening in certain domains, particularly among children of these languages, are unaware of their own language, they have no reading or writing skill.

\section{Historical background}

It is well known that the Sanskrit borrowings in Malayalam have been extensively studied and it's influence have been overpervading in comparision with other languages. The influence of Sanskrit has affected the phonological, morphological and to a lesser extent the syntactic structure of the language. But the lexicon has been influenced by more than $70 \%$ that if one uses a simple sentence in Malayalam, one cannot utter a sentence without using one single item originating from Sanskrit, even though the same concept could be used in the native Dravidian words. The more literary the language, the concentration of the Sanskrit forms would be higher and the more the formal situation arises the use of Sanskrit based items would deemed to be higher. For instance, for a simple concept such as "Transport" in Tamil/ 
pookku varattu / is used, the Malayali, prefers to use/gadaagadaM/, though in Malayalam,/pookz /"to go" and /vard/ could be used. Or, for instance the Malayali prefers to use /aakaaSavaaNi nilayaM/for "Radio station" instead of /vaanoli nilayaM/ as in Tamil. Malayalis also use the words /vaanaM/"sky",/oli/ "sound'. Probably one may call this phenomenon of Tamil as "language purism" as opposed to the non puristic attitude of the Malayalis and the Malayalam language has accepted borrowing and adapted to the situation and has grown, may be due to the historical factors and Tamil has grown intrinsically. Even for a new coinage for scientific word, Malayali seeks for a Sanskrit based lexical item or the Malayali prefers to use a sanskritised lexical item owing to the "prestige factor" involved. History of Malayalam is copious with several examples commencing from early period of $9^{\text {th }}$ Century A.D. that Malayalam could be termed as a language, which is a confluence of the CenTamil on the one hand and the Sanskrit on the other hand with the admixture of native Malayalam elements.But there are, a lot of languages such as Hindi, Marathi, Persian, Hebrew, Arabic, Syrian, Portuguese, French, Dutch and English, which have also influenced Malayalam and from which borrowings and adaptations have taken place .

Earlier studies of loan words in Malayalam have been conducted by GodaVarma(1951) about Indo Aryan loan words in Malayalam and in a very lengthy paper on the influence of Sanskrit in Malayalam, KunjunniRaja(1992), discusses about the borrowings from Sanskrit and Prakrit. As already mentioned the impact of Sanskrit, Prakrit and to a lesser extent Pali is well known. In a nut shell we could say that during the early stages of the development of Malayalam, the over pervading influence of Sanskrit in the literature of Malayalam was dominant, though the $14^{\text {th }}$ Century grammarian of /LiilaatilakaM/,made certain conditioning factors which could be easily understood from the sloka stated below for the /paaTTə/ ${ }^{1}$ type of literature of that period :

\section{draamiDasanghataak\$ara nibandhaM}


eetukamoonavRttaviSee\$ayuktaM paaTTว

The sloka adequately explains that on Dravidian phonematic patterns are unacceptable and that is why we get words such as /ciiraaman/ in the text of "RaamacaritaM", the first literary text of Malayalam(Leelavathi, 1992:19).

Another perceptible development, which has taken place is the impact of Sanskrit on Malayalam and intense borrowing has taken place through Prakrit or Pali. In any contact situation, between languages, normally the internal structure of the language is not affected. But in the case of Sanskrit and Malayalam , the phonological, Morphological and the semantic structure are affected greatly and to very less extent the syntactic structure, probably we could quote the correlative clause construction, which is not a Dravidian structure. /eetว pustakaM eTuttaaluM aa pustakattinz pattu ruupa/" 'Whichever book you take, it is ten Rupees'. This would parallel the Hindi construction /jo bhi pustak aap khariith hai wo pustak ka daam das rupaiya hooga/,but not natural to Malayalam. Similarly due to the impact of English, the passive construction must have come into Malayalam.

maNipRavaaLa Malayalam could be stated as a mixture of Malayalam and Sanskrit, which was happened during the staging of /caakyaaR kuuttz/, a dance drama, performed in the temples of Kerala and the stage, where it is performed is known as /kuuttambalaM/. The viduu\$akan (the buffoon) used to explain the Sanskrit and Prakrit passages from Sanskrit plays in Malayalam, quite often introducing humorous parodies in a macronic mixture of Sanskrit and Malayalam, probably a calque, in modern Linguistic terms, which used to be very popular. The Nampudiri Brahmins, who were great scholars in Sanskrit encouraged and enriched this type of literature. In the early stages due to the conditioning factors the Sanskrit which crept in to the language were mostly tadbhava forms. Gradually when the Sanskrit phonemes also got established in the language, in the literature of Malayalam, there was a free flow of tatsama forms of Sanskrit, which resulted 
in the increase in the forms of Sanskrit items in Malayalam. The language of the elite percolated to the masses, particularly with the advent of press and publication.

\section{Colonization and thereafter}

The arrival of the Portuguese in 1498, followed by the Dutch, the French and lastly the English, further catalysed the borrowing and adaptation phenomena. On the shores of Kerala, gradually they established pockets of settlement and came in direct conflict as well as had friendly terms with the local leaders. A hoard of vocabulary became part and parcel of the life of Kerala inherited from them. But unlike Sanskrit, it did not affect the morphology of the language. For instance due to the impact of Sanskrit, we have words, which could have opposite forms using prefixes /dus-/,

/vi-/. None of the other foreign languages have intruded into the morphological system .

/naTappa/ "conduct",the way one lives etc

/dur-naTappz/ "bad conduct"

lgaNikkz / " to consider"

/vi-gaNikkz/ " not to consider".

The adjectives being expressed using a prefix has also been a contribution due to Sanskrit. For example /su-mukhan/ = nalla mukhamuLLavan 'a man with a good face'. Of course the Dravidian adjective of using /koTu-/ in /kotuveyil/ "severe heat" is prevalent and are few as opposed to Sanskrit.

It is always seen that when two languages come in contact,the first victim is the phonetic and phonological interference, which is perceptibly obvious and noticed. Though the Portuguese landed in Kerala, prior to the Dutch, French and 
English, they did not contribute much to the cultural and linguistic impact in the region, they are remembered for the religious persecution and the contribution as far as language was limited to lexicon. If one uses /paRanki maanna/' fruit of the Cashew nut tree", the word/paRanki/refers to the Portuguese,/fiRanki/. Francis Arakal(2001:449-447) quotes the influence of the Portuguese on Malayalam language and culture. He states that during $15^{\text {th }}$ and $16^{\text {th }}$ century though poetry was the main medium of expression, the Christian missionaries, in their urge to spread Christianity, had studied the language of the people and tried to use prose as a medium of expression and set a new direction in the literary development of Malayalam. The few lexical items that could be mentioned are as follows:

\begin{tabular}{|c|c|c|}
\hline Portuguese & Malayalam & English \\
\hline /gudao/ & /gudaaM/ & 'godown' \\
\hline /leilăo/ & /leelaM/ & 'auction' \\
\hline /mestre/ & /meestari/ & 'mason' \\
\hline /pistolal & /pistal/ & 'pistol' \\
\hline /cozinhal & /kusini/ & "kitchen" \\
\hline $\begin{array}{l}\text { /copal } \\
\text { referred as cc }\end{array}$ & $\begin{array}{l}\text { /kooppal } \\
\text { (akooppa) }\end{array}$ & “cup'(particularly the tea cup \\
\hline ? /penal & /peena / & "Pen”, \\
\hline
\end{tabular}

There are certain questions, regarding the antiquity and origin of these words, because, when exactly the forms have come into Malayalam, whether the source is Portuguese, French or the English. For the controversy of the form regarding /kusini/"Kitchen" in Malayalam, whether it is derived from the Portuguese "cozinho" or French "cuisine". Francis Arakkal(ibid) states it is derived from Portuguese, whereas the English -Malayalam dictionary states the word is derived from French. There are ever so many words 
, which are mired in controversy owing to the lack of written historical documents. In the religious field there are so many words that have crept into Malayalam through Portuguese. To cite a few cathedral, cappela(chapel), patiri, monsignor Loha (the dress worn by the Priest),/Raanthel/(derived from lanterna, according to Francis Arakkal, this was in existence in Europe prior to the arrival of English, the great lexicographer Sreekanteswaram states this is derived from English). The life and work of Rev. Joannes Ernst Hanxleden S.J(1680-1732) popularly known as Arnos Padri brings to our attention the great grammar and lexicographical work he did. He compiled the Portuguese -Malayalam dictionary known as vocabularium malabarico lusitanum. Though the Malayalam language distinguished in speech the long and short /e/, for a long time the orthography did not distinguish it, which was made by the Portuguese.

On $7^{\text {th }}$ Jan, 1663, the Dutch overpowered the Portuguese and became the masters of Cochin Port and the greatest contribution of the Dutch is of a book entitled "hortus malabaricus indicus", written Vaan REID, which deals with the scientific details and medicinal properties of the leaves, roots, seeds and the stems of 725 plants used by the native Malayalis, which has been republished recently is the contribution of Dutch. Originally prepared in Dutch language and had been extensively translated into other European languages. The French also found a small pocket at Mahe, but the impact was not that substantial as the English, who arrived last. The English occupied a small fishing hamlet initially at Anchutengu. They did not directly rule the erstwhile Travancore kingdom but had a domineering presence in the Travancore Kingdom with a resident at Trivandrum. They ruled the Malabar Region under the Madras Province and the influence of English in all walks of life could be seen particularly after the introduction of English education, which was /is considered as a prestige factor and even to this day, the hegemony of English is seen. The establishment of East India company and the presence of English in all walks of life is to be seen as an asset, but our languages have also been influenced due to the impact of English 
and certain marginal phonemes have crept into our phonological system, which could be seen as borrowing and adaptation. For example examine the two phonemes in Malayalam /ph/ and /f/. Ofcourse historically both are not native sounds of Malayalam. These are found only in borrowed words. The Sanskrit based words are used based on the voiceless aspirated bilabial plosive/ $\mathrm{ph} /$ and the other labio dental fricative /f/

See the examples below,

/phalaM/" fruit" (Sanskrit borrowing)

/kaphaM/ "phlegm"( Sanskrit borrowing )

/faan/ "fan" ( borrowing from English )

/koofi kaafi kaappi/ "coffee" ( borrowing from English)

\section{Globalisation ,language attitude and language change}

India as a nation and world at large is under the spell of globalization and the emerging economies such as China, India, Brazil etc are under it's impact. Social science subjects like Economics, Psychology, Law undoubtedly contributes quite a lot to the situation, particularly the study of Stock Markets have become the talk of the town and there is an upsurge in issues concerning corporate law and one wonders what Linguistics or Language studies could essentially contribute to this particular phenomenon (?). But, if, we analyse the changing phenomenon due to the impact of globalization and liberalization in a state like Karnataka or Kerala, you find contradictions. Sometime back, particularly during Gokak movement ${ }^{2}$ there was an anti English agitation and a hue and cry for implementation of Kannada at all level (probably we could term it as an indigenization movement), watch dog committee was set up for implementation of Kannada and still there are stalwarts of Kannada, who plead for effective implementation of Kannada at all levels ${ }^{3}$. This led to even scrapping of English at all level and grants were denied, if schools 
teach in English. Consequent to this there were mushrooming of CBSE schools and many parents admitted their children to such schools. Then the takers of Kannada were poor people in the urban places and the rural folks. But the onslaught of globalization has brought a different scenario now, there seems to be reversal trend. The government wanted to introduce English from first standard (Now the Govt. of Karnataka has actually introduced English from $1^{\text {st }}$ standard). Recent agitations in Karnataka see that there are different groups emerging, some want English to be introduced from First standard particularly the organizations representing backward and under privileged sections and there is a rural vs urban divide on this issue. Particularly after the arrival of the Multi National companies and the establishment of call centres, the demand for adequate skills in English, knowledge and technocrats have hyped the situation. Whereas the Kerala situation is different, there is no die hard attitude towards Malayalam 4 . Nobody is highly bothered as to whether Malayalam, should survive. However the establishment of English medium schools are on the rise. So the emerging sociolinguistic trend is different-the language attitude, maintenance and sustenance of the regional language are issues worth examining. (the accounts are based on the press reports). Recently, in 2015 Kerala Govt. has introduced an order regarding implementation of Malayalam in Administration compulsorily. We are yet to see how effectively they could implement.

In a country as vast as India with a multilingual set up, sustenance and preservation of the national ethos, language and culture were the time tested practices we have been following. Nurturing several languages in the Indian subcontinent had been an herculean task, for the policy framers and language planners and there have been pressures at the formation of State as well as afterwards. Now and then language issue raises it's ugly head. Another unresolved issue, some time ago, the Government of Karnataka faced was regarding the introduction of English from first standard as against the introduction of English from third standard, in the back drop of globalization and liberalization policies pursued by the governments at the Centre and state. In 
the back drop of Globalisation and liberalisation policies, there is an assertion by the intellectual and literary scholars to implement regional languages from class 1 and introduce English at a later stage, but the demand of the parents, have been to introduce it from class 1, even rural folk have also demanded. The main reason being, if one is educated in English, the language of the elite, greater opportunities are there in a globalised world.

Of late the pressures of globalization are giving credence to the fact several parents are admitting their children to English medium schools. Karnataka has achieved remarkable progress in industrial production and agricultural growth and Bangalore had established as the favoured destination for Multi national companies and widely recognized as the global IT hub.

If Kerala has to overcome it's mounting debt burden and solve huge unemployment problem, it has to allow private investment, which means it has to allow global players. It is envisaged that a $10 \%$ growth, which means Foreign direct investment is the need of the hour or Indian private corporate sector. There seems to be paradigm shift as Kerala is opening up in the light of globalization and liberalization policies. The attitude of an average Malayalee is a pragmatic approach towards Malayalam. Not a diehard attitude for the preservation and maintenance, unlike in the case of Kannada in Karnataka. One sees very often agitations in the name of language. There is a Kannada Watch dog committe, to monitor the implementation of kannada. In an earlier empirical study conducted by Nair(1993:13) on the migrant Malayalees in Mysore, it was found that economy of a group plays a very important role as far as the selection of language for higher education. The lower income migrant Malayalee group preferring to opt to learn in Kannada than the higher income, which prefers only English. The second and third generation groups completely preferring to use for all domains of language, only English. So, the scope of the present study is relevant as the hallmark of globalization is felt in economic factors as well as in language. Because the economic factors affect the use of language and 
power and prestige are driven on these matters. Globalisation also brings in along with a dominant mono culture, if one goes to the several malls, which have been established across the country, whether it is Easy Day, Big Bazar, e-Bay etc. See for instance words like smart kitchen, smart phone, smart office, smart city etc. where the word "smart" has evolved as a representative of a monoculture, a universal phenomenon. The word 'smart' is also written as /smaaRTTə/ in Malayalam(mathrubhumi newspaper dtd 9-122015, p.9).

\section{Significance of Computer}

Another important factor is the information superhighway, which has been accentuated, as the bearer of explosion of knowledge. Today, in seconds, one is aware of what is happening across the globe, but the language which is used is English and it has been the lingua franca in all communications. It is considered as the language of wider communication and global language (See David Crystal:1997). The end of the cold war coupled with the remarkable transnational net work connectivity have accelerated the growth of English as a global language. What are the consequences of a single language becoming a global language?. Definitely there will be marginalization of other languages and possible endangerment of several other languages and naturally several cultures, as language and culture are two sides of a coin. So it is necessary for every community of speakers of any language to take adequate steps to preserve and protect their language. Thomason(2001:24) as quoted in Wright(2004:134) states that "the status of a lingua franca depends most obviously on history's ups and downs : if people who hold political and economic power lose their power their language is likely to lose it's status for international communication."

Andrewskutty(2005) in his study on Globalisation and language: A case study of Malayalam remarks that an average Malayali with out getting bogged into the sentiments attached to the Malayalam loyalists or the anti English medium propagandists 
takes a practical decision with regard to his survival and is very adaptive to the circumstances.

When the Government of India and other state governments have become signatories to IMF, GATT, WTF, IMF, Human Rights Commission etc, and the funds we have received from ASIAN DEVELOPMENT BANK, we should realize that the economy and other polity are partially designed from across the borders and we have to succumb to the monopolistic imperialist designs. Globalization is an offshoot of these designs. Can we call that the sovereignity of the state is at peril and international organization have a say in our day to day matters and English has become the global language and all other languages are at stake? If so, can we say the linguistic rights of minority languages are protected at all levels. Please refer to Nair (2001) for further elucidation on linguistic rights of minorities. What exactly is globalization? Is it economic globalization. It is believed that once the policies of globalization are accomplished, we would have better place to live in. But the stark reality is the gap between the rich and poor are widened and the minor and minority languages are further marginalized. English as a global language has enriched it's position for all transnational activity. Unless and until all Indian languages find a place in higher education set up there is every possibility that English would replace it. The hegemonistic tenedencies of English have been further detailed in Dua(1994). One of the important consequence of this would be that Translation across languages has to grow exponentially, which would enhance the growth of languages across the world. Every language speaker should have to protect and preserve his or her language for sustenance and growth, whether big or small.

Fukuyama (1989) brings in the end of history thesis which is the downfall of Communism, the end of the cold war era, the disintegration of Soviet Union and the ascendancy of the sole super power, the United States of America. The globalization in the garb of global capitalism has no challengers. One important consequence of the effect of globalization is that there is greater 
contact between language groups through transnational net working. As opposed to ASCI system, UNICODE system would pave a better way for global accessibility among language groups. Then, one can witness that indigenous languages develop and towards this phenomenal development all have to strive. However, it will largely depend upon political developments and the position of global economy.

The language movements under the leadership of Mahatma Gandhi gave primacy for education at all levels, was in regional languages. The post independence Scenario, when the nation building had taken place and is taking place, the role of regional languages was emphasised. The accepted three language formula consisting of the Hindi/mother tongue(in Non-Hindi regions),English, Hindi. Post cold war era and the post Globalisation and liberalisation saw the emergence of English , as a language of significant impact that the regional and tribal languages are getting marginalised and probably endangerment as there seems to be not only language loss but also native cultural elements are getting obliterated.

\section{Lexical borrowings and adaptations into Malayalam ( with reference to media)}

A cursory analysis of the Malayalam Lexicon in any Newspaper would bring to the fore the impact of English in everyday communication. This predominant and hegemonistic use of English reveals that the news paper is written for an elite audience and not for the common masses or an elite bilingualism is the order of the day and the masses who are not competent to that extent are mere consumers. The communicative competence of the masses is very minimal. The consequence of this situation is that a large number of words of English are being adopted and naturalized. The present paper would examine with an empirical study of such a situation and analyze the larger sociolinguistic factors of Language Purism, Mass bilingualism by comparing with other factors such as Globalisation. The earlier impact of English has been felt during the colonial period. The post independence 
period has seen a revival of indigenous languages, establishment of State Institute of languages, the need for higher education in Malayalam and translation of Science subjects in Malayalam, development of scientific and technical terms etc. This is not only true of Malayalam. It happened in several states. Of course in the state of Tamil Nadu, a political movement led by Dravida Munnetra Kazhakam (DMK) and other parties on the one hand (anti Brahmin movement) and the middle class uprising against the British domination has catalyzed a language purism movement in Tamil.

Consequent to the impact of globalization, apart from the earlier impact of English in the body polity of Malayalam Language and culture, yet another impact that one could expect is the colonization of the conscience of a global language and culture and how media is adding to it. An analysis of several programmes telecast by several channels is a pointer to this. The Malayalam language used by the comperer has been largely eroded.

There is dramatic change with regard to the means in which communication is effected as opposed to the earlier days. In olden days the folk literature played a dominant role and the means in which it was effected was the oral medium. With the advent of printing, reading developed and it further catalyzed the awareness coupled with the literacy drive. Later the audio medium, was radio and in a recent thesis submitted and awarded to Parameswaran (2006), he has stated that even today the radio plays a dominant role among the vast majority of the people of Kerala.

The use of English in mass media such as Malayalam movies, drama etc is very minimal in comparison with the use of English in advertisements or TV media or in newspaper. Newspaper borrows and adopts English in Malayalam dailies to a very large extent that its use has become a norm. It gets percolated to the masses easily and adopted. But the question remains as to whether all the consumers are able to comprehend the terms used in the dailies. Due to the constant use of English as a code switching behaviour of the educated mass (elite group), there is predominant use of English in every walks of life. It is this 
elite bilingualism as opposed to the mass bilingualism which is taken up for the study in this paper. There have been language movements in many parts of the world and language purism has become a serious debate on such occasions. It was essentially in the context of cultural erosions which have happened or national awakening. The Malayalee psyche is more of an adoptive or adaptive culture and on very few occasions there have been Linguistic purist efforts.

\section{Data}

The data presented here is a sample one from a News paper and another one with frequency count is the corpora of Malayalam (lexical items listed in TDIL corpora of 10 lakh and odd words).

\section{RESULTS AND DISCUSSION}

The analysis shows the lexicon of Malayalam which is presented could be classified into three categories, one which has become so naturalized to Malayalam, probably the least educated person also without any inhibition would be using particularly the words such as driver, bus, car, lorry, radio, hospital with modification such as /aaspatRi/ or receipt as /resiiti/. Later on such lexical items as sports, magic, clerk even though there are equivalent terms available in Malayalam and could be predominantly used and some of which are rarely used. The data is quantified with available Malayalam Corpora. Another category of lexical items which are of recent adoption. See for examples such as sensex point, steering collapsed, to overtake etc, it is more of transliteration of the English words in Malayalam alphabets and many verbs are of the kind such as a noun incorporated form with a verbalizer such as

/ceyya /'to do'

to suspend - /saspenRz ceyyz/

to nominate -/noomineeRRu ceyyd/ 
This is a predominant behavior in several Indian languages, to use verbalizer whenever English interferes such verb+paNNu in Tamil or verb + maaDu in Kannada. But as opposed to Tamil and Kannada, the liberal use of English in day to day communication and particularly in the media is very high. There is no puritanical efforts on the part of Malayalam and its speakers to correct such a situation and over a period of time an apprehension is, it may be gobbled by English. Globalization is adding an impetus to such a situation and the marginalization of local culture and language is on the rise. See the data in Appendix 1 and 11 for better elucidation.

An analysis of the Idea star singer programme which was being telecast shows even the sentences turns out to be a code switching situation of English and Malayalam. The language of advertisements, if analysed shows a mixture of Hindi, English and Tamil. .The effect of audio-visual medium is said to be $80 \%$ compared to the print medium which is $20 \%$. Communication through the media controls the mind and there is a process of natural acquisition and the language of the individual would largely depend on this. The last category of lexical items are new introductions to the language which even the semi educated fail to capture, see for instance the lexical items such as /ombudsman/, /noom/etc. In the early stages of English education or English interference, people had translated many terms such as for "train" as /tii vaNTi/ or /puka vaNTi/, "post office" as /tapaal offiissz/, "post box" as /tapaal peTTi/, "post man" as/tapaal Sipaayi/. These terms have almost become obsolete and are being replaced by the transliteration of English in Malayalam.

Broadly lexical transfer could be classified into five types: 1) Lexical transfer with out any form change 2) the form being transferred to the target language with minor modifications 3 ) the loan word word is literally transfered by translating the term in the target language or lexical paraphrase 4) semantic shift taking place 5) word coinage

The following words in English are transferred to Malyalam 
without any change. /ReeDiyo/"Radio", /Telivi\$̦an/"telivision', / fRiDja/' fridge"

As per the second variety from English we also get variant forms as spoken by educated versus uneducated. For example ,formally educated variety of the lexical item for doctor will be /DookTaR/,whereas the uneducated variety would be / DaakkiTTaR/.

For" station" it will be /sRee\$an $\sim$ Tee\$an/, /DRaivaR DaivaR/, /lipsRik lipTik/etc

/cuvappu naada/ is a literal translation of "redtape".Very often, particularly in the northern part of Kerala, people use the form "wife house" which is a lexical paraphrase of /bhaarya viiDa/.

There are several words in Sanskrit which have been borrowed into Malayalam, where in a meaning change has occurred in Malayalam, we could state it as Semantic shift. The original meaning of Sik\$a is "instruction, study, discipline". Malayalam uses /Sik\$a/ in the primary sense of "punishment" and /vidyaabhyaasaM/is used as 'education"

Word coinage forms another important category in the lexical transfer which have taken place from English to Malayalam. It is seen that a prestige factor is also involved while a particular person is using a smattering of English, mostly it shows a person is slightly advanced or educated and he uses a mixture language. See the examples shown below ;

cikkaN kaDa "chicken shop" mutton kaDa "mutton shop"

* fish kaDa But nobody uses this combination, it is generally two Malayalam words are used and we get the word/miin kaDa/ "shop where fish is sold. As per KairaLi news the following words were noted down : 
STD kaalukaL "STD calls" (English word +Mal pl.form)

kaaL nirakkukal "call rates"(Eng.word +Malword+Mal.pl)

kaaLukaLuTe eNNaM" the number of calls"(Eng word+Mal. pl+Mal.Gen.+Mal )

siRRi bassukaL "city buses" (Eng.word+Eng.word+Mal.pl)

maaRccu naTatti 'the marches were conducted'(Eng.Word + Mal.Verbalizer) word)

cunkattu juuvalRi "Chungath Jewellery"(Mal.+Mal.Case+Eng.

RimaanRu ceytu " kept in Remand"(Eng.word +Mal Verbalizer)

The above data show the amount of impact of English in the Malayalam media and how it has invaded the structure of Malayalam. In the word 'STD calls' other than the plural form /-kaL/, the other words are in English. In the second item the word for "rates" is in Malayalam. The word for call is /viLi/. Atleast in a Drama of C.L. Jose, it is attested. Another important feature is the verbalizer such as/naTattz/, /ceyyz/, which parallel the word /kaRna/ in Hindi or /maaDu/ in Kannada, being used with the English word. This clearly indicates that the loan words and the structural changes that are happening in Malayalam is a fit case for further investigation for language change.

\section{LANGUAGE PURISM}

Language purism was not only found in Tamil (Annamalai, 1979) or Marathi as reported in the press during the period from (November,1983 to February, 1994) but there have movements for Sinhalese in Sri Lanka or for an assertion of Australian English as opposed to British English or American English (as reported in (Jernudd and Shapiro,1989). There have been candid efforts in Malayalam too during the sixties and seventies by the late poet, 
Sri.N.V. Krishna Variar and founder Director of the State Institute of Languages. Another effort by State Institute of Languages is / malyaaLa tanima/ (original Malayalam)some years back. But the contribution from media would be immense, if it could make a change in this direction. It is seen the frequency count for the listed 121 items, of which only a sample is presented here, is very high. From the corpora, it is also to be accounted that the frequency count for the word 'library' is higher than the native word 'granthaSaala'. Language practitioners, Linguists, Translators from English to Malayalam or Malayalam to English, may take note of the changing phases of Malayalam. 


\section{APPENDIX 1}

SAMPLE DATA (based on 24 ${ }^{\text {th }}$ January, 2008 'mathrubhumi news

Words naturalised

/spooRts/

'sports

/maajik/

'magic'

/baankə/

/klaRkkə/

/bessə/

'Bus'

/looRi/

'Lorry'

/aaspatRi/

'hospital'

/bass dRaivaR/

'Bus driver'

/resiiti/

'receipt' paper)

Words recently

adopted

/sensex pooyanRə/

'Sensex point'

/stiyaRin takaRnnu/

'steering collapsed'

/oover teekku ceytu/

'overtook'

/RippaR looRi/

'Ripper lorry'

/Riseevə palifa/

'reserve interest'

/kloossu ceytu/

'closed'

/saspendu ceytu/

'suspended'

/kRaim bRaancə /

'crime branch'

/ no om in e e R R u

ceytu/

'nominated'
New words

/ombudsmaane/

' of ombudsman'

/graaniRRu

pRadaRJanaM/

'granite

exhibition'

/viLambaan

ooRdaR veeNaM/

'need permission

to serve'

/nooms/

'norms' 


\begin{tabular}{|c|c|}
\hline \multicolumn{2}{|c|}{ Idea star singer programme(tv programme) } \\
\hline $\begin{array}{l}\text { /itu fooRth rauND } \\
\text { aaNO/ }\end{array}$ & $\begin{array}{l}\text { /namukku } \\
\text { peRfoRmansu } \\
\text { rauNDileeykku } \\
\text { kadakkaaM/ } \\
\text { 'Let us enter the } \\
\text { performance round' }\end{array}$ \\
\hline $\begin{array}{l}\text { 'This is fourth round' } \\
\text { /itə inTeraaksan } \\
\text { koosRRyuum ,pRasanree } \int a n \\
\text { rauNDaaNə / } \\
\text { 'This is Costume,presentation } \\
\text { round" }\end{array}$ & $\begin{array}{l}\text { /auT af sevenRi } \\
\text { etRa maarksaaNo } \\
\text { nammaLkkujadjinooTu } \\
\text { coodiccu nookkaaM/ } \\
\text { Let us ask the judge } \\
\text { that out of seventy } \\
\text { how many marks have } \\
\text { been scored' }\end{array}$ \\
\hline
\end{tabular}




\section{APPENDIX-11}

LEXICAL BORROWING OF ENGLISH WORDS TO MALAYALAM BASED ON FREQUENCY COUNT in decreasing order - Technology Development in Indian Languages CORPORA, from CIIL, Mysore:

TOTAL NO. OF WORDS : $\quad 10,93,711$

TOTAL NO.OF SENTENCES: $\quad 3,57,588$

THE PRESENT STUDY HIGHLIGHTS ONLY THE FIRST 3000 WORDS IN MALAYALAM, WHICH IS INCLUSIVE OF BORROWED ENGLISH WORDS PERCENTAGE OF BORROWING $=4.033 \%$ ie. $121 / 3000$. (sample examples listed from 121 items) The frequency count above 100 is very high, above 50 and below 100 is medium and below 50 is low.

\begin{tabular}{|l|l|l|l|}
\hline $\begin{array}{l}\text { ENGLISH } \\
\text { LEXICAL ITEM } \\
\text { BOOROWED in } \\
\text { MALAYALAM }\end{array}$ & $\begin{array}{l}\text { FREQUENCY } \\
\text { COUNT }\end{array}$ & $\begin{array}{l}\text { E NGLISH } \\
\text { LEXICAL ITEM } \\
\text { BORROWED IN } \\
\text { MALAYALAM }\end{array}$ & $\begin{array}{l}\text { FREQUENCY } \\
\text { COUNT }\end{array}$ \\
\hline $\begin{array}{l}\text { /gaveeNmentə/ } \\
\text { government' }\end{array}$ & 1300 & /oof/'off' & 506 \\
\hline /miittar/'meter' & 721 & $\begin{array}{l}\text { /poolissə / } \\
\text { 'police' }\end{array}$ & 391 \\
\hline $\begin{array}{l}\text { /ameerikkan/ } \\
\text { 'American' }\end{array}$ & 353 & $\begin{array}{l}\text { /kaaRbaN/ } \\
\text { 'carbon' }\end{array}$ & 338 \\
\hline $\begin{array}{l}\text { /haidRajan/ } \\
\text { 'Hydrojan' }\end{array}$ & 268 & $\begin{array}{l}\text { /dookTaR/ } \\
\text { 'doctor' }\end{array}$ & 261 \\
\hline $\begin{array}{l}\text { /rejistaR/ } \\
\text { 'Register' }\end{array}$ & 258 & $\begin{array}{l}\text { /RippooRTTə/ } \\
\text { 'Report' }\end{array}$ & 253 \\
\hline
\end{tabular}




\begin{tabular}{|l|l|l|l|}
\hline $\begin{array}{l}\text { /kiloograaM/ } \\
\text { 'kilogram' }\end{array}$ & 241 & /uunian/'union' & 219 \\
\hline $\begin{array}{l}\text { /ilaktRooN/ } \\
\text { 'electron' }\end{array}$ & 212 & /TaN/'Ton' & 206 \\
\hline $\begin{array}{l}\text { /nambaR/ } \\
\text { 'number' }\end{array}$ & 199 & $\begin{array}{l}\text { /prooTiin/ } \\
\text { 'protein' }\end{array}$ & 195 \\
\hline
\end{tabular}

\section{NOTES:}

1. A type of poetic metre prevalent during $11^{\text {th }}$ Cent. A.D. to 14th cent. A.D. in Malayalam

2. Kannada Language Movement in Karnataka (Regional language vs. English)

3. Writers and intellectuals are against granting permission for commencing 350 English medium schools, Hindu News paper dt 06-06-12, whereas Dalits support the move on English in Schools, Hindu newspaper dt08-06-12. The Dalits urge the govt. to commence English medium from $1^{\text {st }}$ standard.

4. Mathrubhumi News paper report of 06-06-12 shows the Malayalam speakers are more pragmatic in their approach and raises the question of how jobs would be created if a person studies Malayalam, he would be confined to Kerala and would not be in a position job opportunities outside.

\section{REFERENCES}

- Andrewskutty, A.P. (2005): http://www.clickeralam.org/ resourcesAndrew.html

- Annamalai, E; 1979: Movements for Linguistic purism. The case of Tamil: in "Language Movements in India, Mysore: CIIL

- Crystal, David (1997): English as a global language: Cambridge: 
Cambridge University Press

- Dua, Hans Raj (1994) : Hegemony of English. Mysore : Yashoda Publications.

- Francis, Arakkal (2001): 'The influence of Portuguese in Medieval Malayalam' in Ed. Mathew, K.S. et.al. The Portuguese and the Sociocultural changes in India, 1500-1800, pp449-467, Tellicherry: pub. IRISH, Godavarma,K(1946):Indo-AryanLoan words in Malayalam. Mavelikara: RamaVarma\& bros

- Jernudd, Bjorn. H,1989: The Politics of Purism, New York: Mouton de Gruyter \&Michael Shapiro.

- Kunjunni Raja, K(1992): 'Sanskrit Influence on, InternationalJournal of Dravidian Linguistics. Vol. XXI. No. 2. p. 50-105.

- Leelavathi,M (1992): History of Malayalam poetic literature. (malayaala kavita saahitya caritRaM).Trissur Kerala Sahitya Academy[ in Malayalam]

- Nair, V. Saratchandran: 'Migrant Malayalees in Mysore, A case study of language Related issues' Pondicherry Journal of DravidicStudies;3:1,pp.1-15.

- Nair,V.Saratchandran:'Linguistic Rights of Minorities and Social Justice', in PondicherryJournalDravidicStudies, 11:1,11:2;93-98.

- Parameswaran, 2006: 'Language of Mass Media study based on Malayalam radio Broadcasts'. Ph.D. thesis., Kerala University

- Wright, Sue (2004): Language policy and Language planning From nationalism to globalization., New york: Palmgrave, Macmillan 